\title{
COMPOSIÇÃO DO MICROFITOPLÂNCTON DO ESTUÁRIO DO RIO IGARASSU (PERNAMBUCO) *
}

\author{
ENIDE ESKINAZI-LECA, JOSÉ ZANON DE OLIVEIRA PASSAVANTE \\ Departamento de Oceanografia, Universidade Federal de Pernambuco, Recife, PE, Brasil
}

LUCY MOREIRA B. FRANÇA

Departamento de Biologia, Universidade Federal Rural de Pernambuco, Recife PE, Brasil

\section{SYNOPSIS}

This paper reports a quali - and quantitative study on phytoplankton occuring in the estuary of Igarassu river (Lat. $7^{\prime} 49^{\prime} S \cdot 34^{\circ} 52^{\prime} W$ ), one of the must important in the Itamaraca region $(50 \mathrm{~km}$ north of Recife, PE, Brazil). Samples were taken during the period May, 1973 10 May, 1974. Forty two species of diatoms were identified and listed, representing the most frequent group of the marine microalgae col. lected. Special emphasis is given to the ecological conditions of the estuary.

\section{Introdução}

Vários autores têm salientado a importáncia do estudo do fitopláncton em regiões estuarinas, em virtude ao aumento natural dessas populaçōes, o qual ocasiona uma maior produtividade nos estuários, tornando-os áreas de importáncia econômica (Riley, 1952; Hulburt, 1956; Patrick, 1967; Tundisi, 1970).

Lntretanto, os estudos ecológicos em regiōes estuarinas ainda não alcançaram no nordeste do Brasil o desenvolvimento que merecem, levando-se em conta a quantidade de rios que existem e que representam recursos naturais de incalculáveis riquezas.

Atualmente, porém, em virtude da demanda cada vez crescente de alimento, as instituições de pesquisas, apoiadas pelo Governo, vêm iniciando uma série de estudos bioecológicos em corpos de águas estuarinas, visando um melhor aproveitamento dos recur(5) naturais existentes.

Exemplo disto, é o que vem sendo realizado na região de Itamaracá $(50 \mathrm{~km}$ ao norte de Recife), onde o Departamento de Oceanografia da Universidade Federal de Pernambuco, apoiado pela SUDENE e FINEP, vem desenvolvendo um vasto plano de pesquisa no Canal de Santa Cruz e estuários adjacentes, visando o levantamento dos recursos pesqueiros ocorrentes e desenvolvimento de técnicas de cultivo para um aproveitamento racional destes recursos.

A presente pesquisa faz parte do plano de trabalho desenvolvido na região de Itamaracá e tem por finalidade o estudo qualitutıvo e quantitativo do fitoplâncton, do estuário do rio Igarassu, um dos mais importantes da região de Itamaracá, tendo sido dada :pecial atenção as condições ecológicas do estuário.

Os resultados obtidos servirão assim de base aos trabalhos sperimentais que se desenvolvem na região de Itamaracá, principalmente quanto ao fato das águas do rio Igarassu estarem recebendo residuos industrias que poderão, em futuro próximo, influir nas nutáveis condições de vida que o Canal de Santa Cruz atualmente upresenta.

\section{Material e métodos}

Foram coletadas amostras mensais de plâncton em três estaCões fixas, durante o período de maio/73 a maio/74 (Fig. 1). Para us coletas foi usada uma rede de náilon, com malha de 65 micrômetros, a qual foi arrastada horizontalmente na superfície da água durante 5 minutos. As amostras foram fixadas com formol neutro a $4 \%$. Para a identificação das diatomáceas foram confeccionadas lâminas de acordo com o método de Müller-Melchers \& Ferrando (1956).

\section{Localização e descrição geral da área}

O estuário do rio Igarassu está localizado no litoral norte do Estado de Pernambuco $\left(7^{\circ} 49^{\prime}\right.$ Lat S, $\left.34^{\circ} 52^{\prime} \mathrm{W}\right)$, comunicando-se com o mar através do Canal de Santa Cruz (Fig. 1). Está situado em região tropical, distinguindo-se duas estações: uma estação chuvosa (de março a agosto), com precipitações mensais acima de $100 \mathrm{~mm}$ e uma estação seca (setembró a fevereiro), com precipitações abaixo de $100 \mathrm{~mm}$.

Do ponto de vista hidrológico a área foi bem descrita por Macêdo et al. (1973) e Paranaguá et al. (no prelo), dos quais foram tiradas algumas informaçōes sobre as características hidrológicas da área.

Temperatura da água: não apresenta grande margem de variação, tanto na superfície como no fundo. A temperatura máxima gira em torno de $30^{\circ} \mathrm{C}$ e a mínima em torno de $24^{\circ} \mathrm{C}$. Os mais altos indices correspondem aos meses ae janeiro e fevereiro, dimi nuindo a partir de março, até atingir os valores mínimbs nos meses de junho e julho.

Salinidade: o estuário apresenta um regime de salinidade marinho polialino até mesoalino. De uma maneira geral, os teores decrescem da estação 4 para a estação 6 , sendo esta estação onde ocorrem os menores valores, devido à maior influência da água fluvial. As mais altas salinidades correspondem aos meses de janeiro e fevereiro, com o valor máximo de $37,03 \%$. Os baixos valores estâo associados às grandes precipitaçōes pluviometricas e ocorrem geralmente na estação 6 , com o mínimo de $5,57 \%$.

Oxigênio dissolvido: as concentrações de oxigênio dissolvido apresentam concentrações normais, com teores que oscilam entre $4,97 \mathrm{ml} / 1$ a $3,31 \mathrm{ml} / 1$. As mais baixas concentrações são registradas nas estações 5 e 6 , em conseqüência da grande quantidade de material em suspensão transportado pelo rio.

\section{Resultados}

Os resultados dados a conhecer na presente pesquisa são produtos de uma análise geral sobre o fitoplâncton, obtidos durante um ano de amostragens, os quais deverão ser complementados com análises mais profundas, dirigiaas principalmente à obtenção de maiores conhecimentos sobre o ciclo anual, composição específica, distribuição vertical do fitoplâncton, como também a influência dos fatores abióticos sobre esta comunidade vegetal.

\section{Composição do microfitoplâncton}

Vários grupos de microalgas foram identificados, destacando-se as diatomáceas, dinoflagelados, cianofíceas, euglen ofíceas, clorofíceas. Destes grupos, o que apresentou maior número de espécies foi o das diatomáceas, tendo sido identificadas as seguintes espécies, relacionadas abaixo com os dados ecológicos de cada uma:

1 - Achnanthes brevipes Agardh

Espćcie marinha, litoral, mesoalóbia a eualóbia. Eurialina.

2 - Amphiprora alata (Ehr.) Kutzing

Espécie marinha, litoral e mesoalóbia.

3 - Amphora angusta Gregory

Espécie marinha, litoral, polialóbia. Eurialina

4 - Asterionella japonica Cleve

Espécie marinha, planctônica, nerítica

5 - Bacteriastrum delicatulum Cleve Espécie marinha, planctônica, nerítica

6 - Bellerochea malleus (Bright.) Van Heurck

Espécie marinha, planctônica, nerítica

7 - Biddulphia mobiliensis (Bail.) Grunow Espécie marinha, nerito-oceânica, polialóbia

8 - Biddulphia regia (Schultze) Ostenfeld Espécie marinha, planctônica. Eurralina.. Bastante abundante no fitoplâncton do Canal de Santa Cruz.

9 - Cerataulina pelágica (Cleve) Hendery Espécie marinha, planctônica, nerítica. Eurialina. Freqüente em regiões estuarinas, baías e lagunas.

10 - Chaetoceros coarctatus Lauder Espécie marinha, oceânica, planctónica.

11 - Chaetoceros curvisetus Cleve Espécie marinha, planctonica,neritica

12 - Cocconeis scutellum Ehrenberg Especie marinha, litoral. 


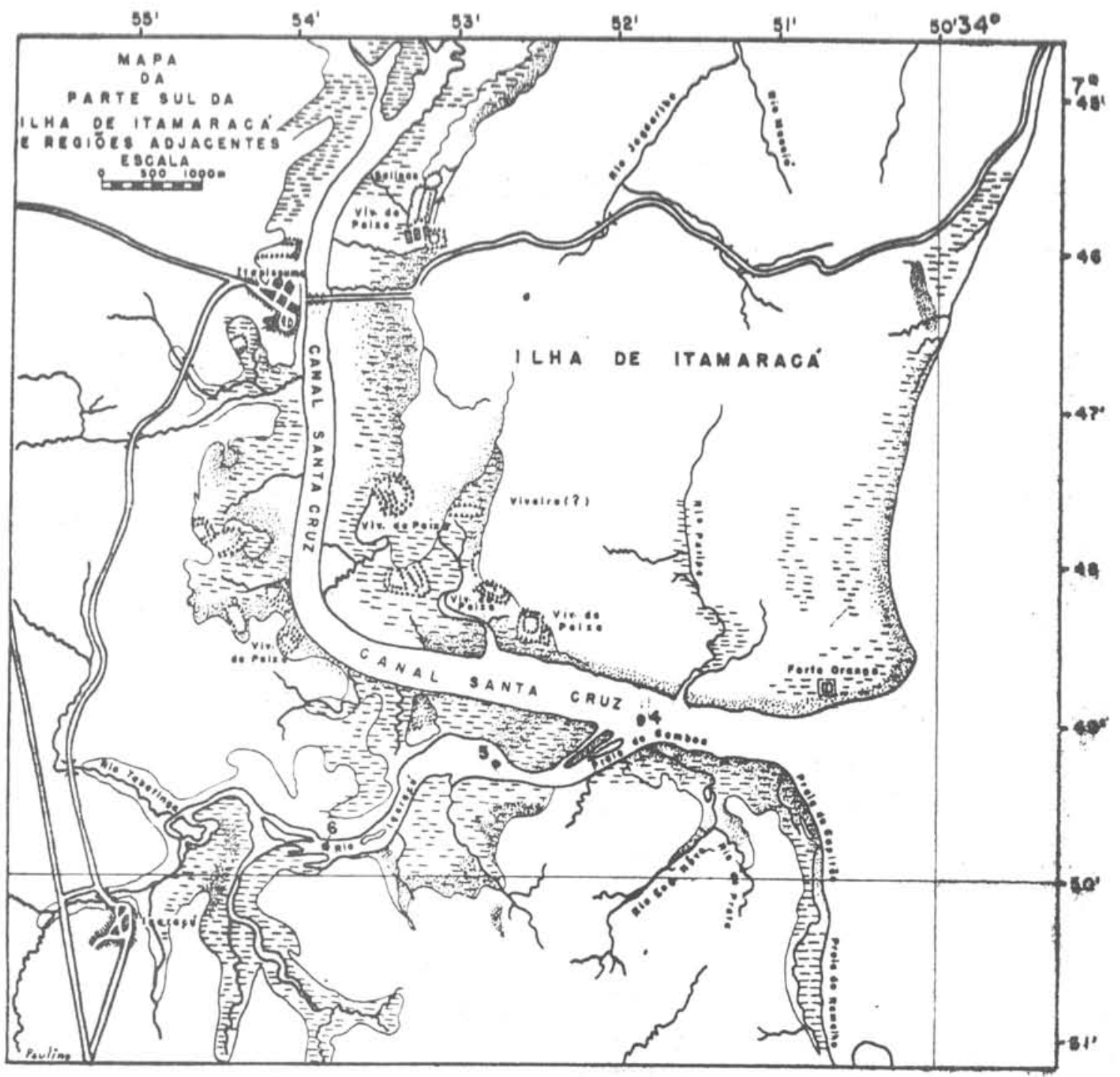

Fig. 1- Mapa de localizaçäo das estaçōes

13 - Corethron hystrix Hen.

14 - Coscinodiscus centralis Ehrenberg Espécie marinha, nerito-oceânica.

E uma das espécies mais abundantes do microfitoplâncton do Canal de Santa Cruz.

15 - Cyclotella stryllorum Brightwell Espécie marinha, litoral.

16 - Diploneis bombus Husted Espécie marinha, litoral.

17 - Ditylum brightwelli (West.) Grunow Espécie marinha, planctônica,nerítica.

18 - Gramatophora marina (Lyng.) Espécie marinha, litoral.

19 - Gyrosigma balticum (Ehr.) Rabenh.

Espécie de águas salobras, encontradas em estuários e lagunas costeiras.

20 - Leptocilyndrus danicus Cleve

Espécie marinha, planctônica,nerítica.

21 - Lithodesmium undulatus Ehrenberg

Espécie marinha, planctônica, nerítica.

22 - Melosira moniliformis (O. Muller) Agardh

Espécie marinha, litoral, mesoalóbia.

Eurihalina, também encontrada em águas salobras.

23 - Nitzchia closterium Ehr. (W. Sm.)

Espécie marinha, litoral.

24 - Nitzchia granulata Grunow

Espéçie marinha. litoral. Também encontrada em estuário. Mesoalóbia e eurialina.

25 - Nitzchia longissima (Breb.) Ralfs.

Espécie marinha, litoral.

26 - Nitzchia paradoxa (Gmel.) Grunow

Espécie marinha, litoral. Eurialina.
27 - Nitzchia punctata (W. Sm.) Grunow Espécie marinha, litoral.

28 - Nitzchia sigma Kutz. (W. Sm.) Espécie marinha, litoral. Eurialina.

29 - Rhizosolenia calcar-avis Schultze Espécie marinha, planctônica pelágica.

30 - Rhiz, imbricata var. shrubsolei (C1.) Schroder Espécie marinha, planctônica nerítica.

31 - Rhizosolenia setigera Bright. Espécie marinha, planctônica nerítica.

32 - Rhiz. setigera var. daga (Brigh.) M. Melchers Espécie marinha, planctônica. Polialóbia.

33 - Rhizosolenia stolterfothii Peragallo Espécie marinha, planctônica nerítica.

34 - Skeletonema costatum (Greville)' Cleve Espécie marinha, nerítica. Eurialina. e euriterma.

35 - Surirella febigerii Lewis Espécie marinha nerítica. Eurialina.

36 - Surirella gemma Ehrenberg Espécie marinha nerítica. Eurialina.

37 - Thalassionema nitzschioides Grunow Espécie marinha nerítica, planctônica.

38 - Thalassiotrix frauenfeldii (Grunow) Cleve Espécie marinha, oceânica.

39 - Terpsinoe musica Ehrenberg

Espécie de ampla distribuição em águas salobras. Mesoalóbia e eurihalina.

40 - Triceratium contortum Shadbolt

Espécie marinha, litoral.

41 - Triceratium favus Ehrenberg

Espécie marinha, nerítica. Eurialina.

42 - Tropidoneis seriata Cleve 
Espécie marinha, nerıtıca.

Os dinoflagelados formaram um grupo pouco freqüente e com pouca significação no microfitoplâncton. Foram representados pelos gêneros Ceratium, Peridinium e Prorocentrum, os quais tiveram melhor representação na estação 4 .

As cianofíceas também foram pouco significativas, não apresentando importância quantitativa em nenhuma das estaçōes estudadas. Ocorreram Oscillatoria, Lyngbya, Anabaena e Meris. mopedia.
As clorofíceas e euglenoficeas faram as algas planctônicas de menor significado e por isto não foram submetidas a análises taxonômicas abaixo de gênero.

Entre as espécies identificadas, quatro foram qualitativamente importantes pela regularidade de freqüência, aparecendo algumas vezes em altas percentagens. Foram elas: Coscinodiscus centralis, Biddulphia regia, Chaetoceros sp. e Rhizosolenia setigere var, daga (Figs 2, 3, 4.).

Por outro lado, relecionando-se o que se passa nas três estaçס̃es, observa-se que existe um certo paralelismo quanto à

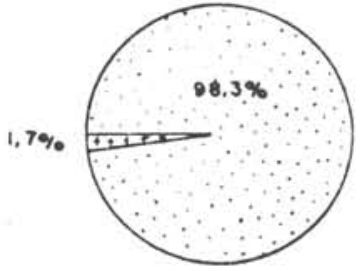

MAI.

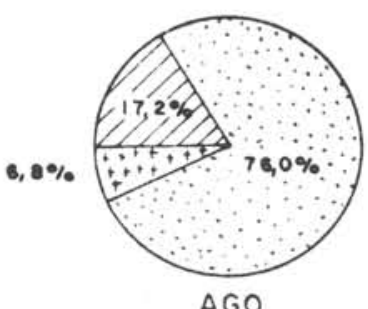

$A G O$

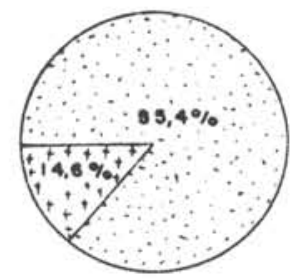

DEZ

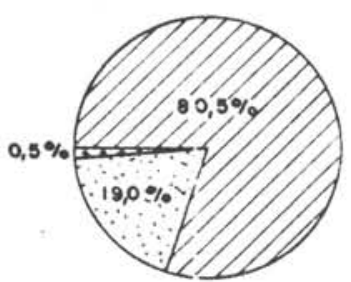

MAR.

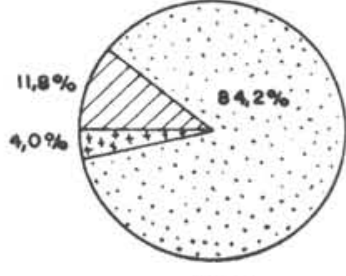

JUN.

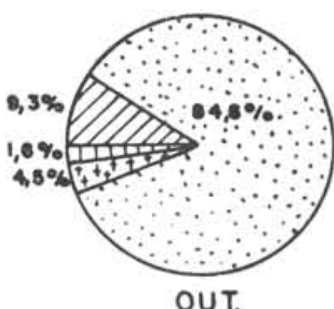

OUT.
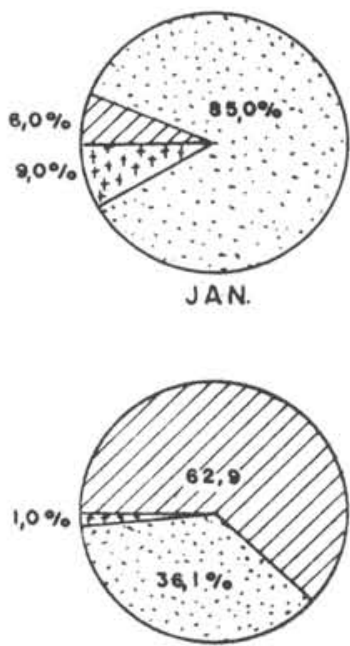

$A B R$.
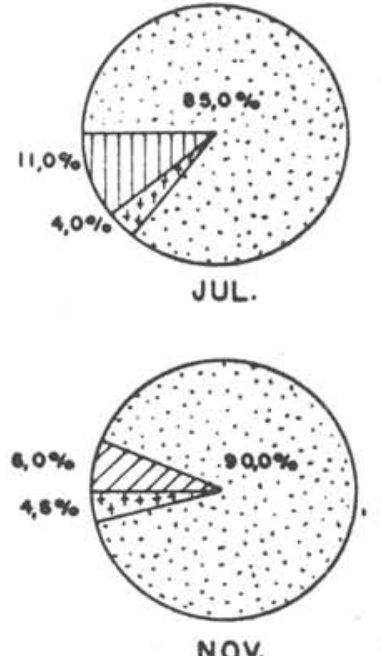

NOV.
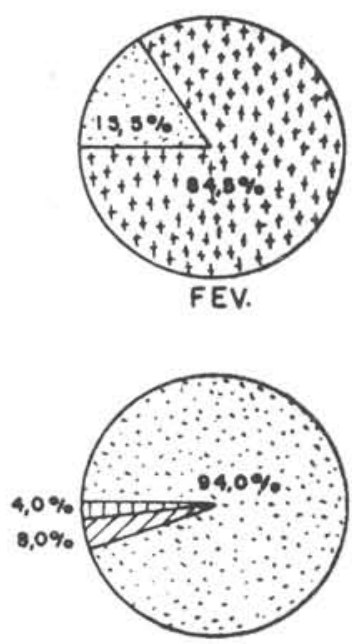

MAI.

\section{Biddulphia regia}

Coscinodiscus centralis

(t+i) Outros diatomóceos

(I) Outros microolgos

Fig. 2 -Principais componentes do microfitoplancton, ocorrentes no estação $\mathbb{Z}$, durante o periodo de maiol 73 a maio/74. 


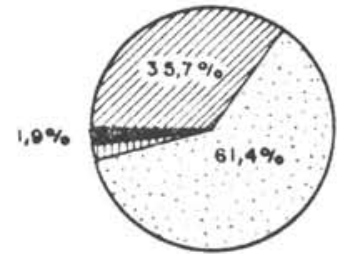

MAI.

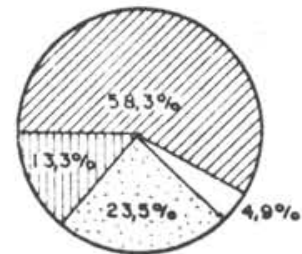

AGO.

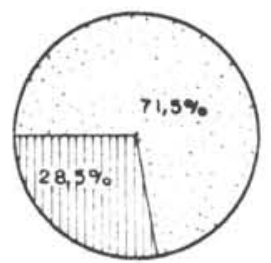

DEZ.

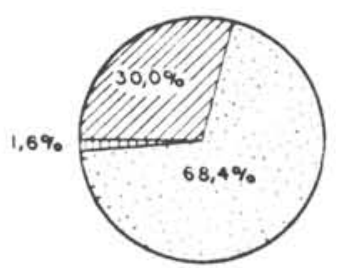

MAR.

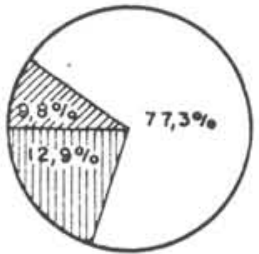

JUN.

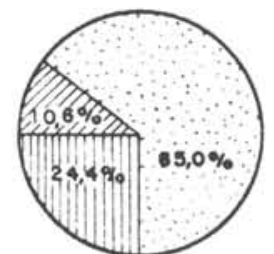

OUT.

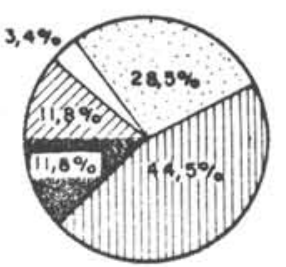

JAN.

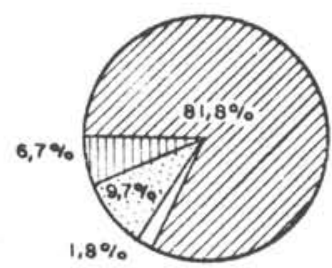

$A B R$.

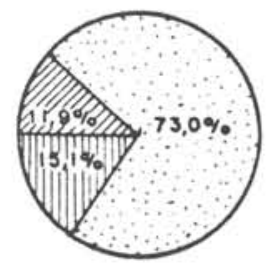

JUL.

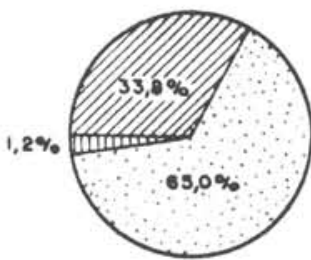

NOV.

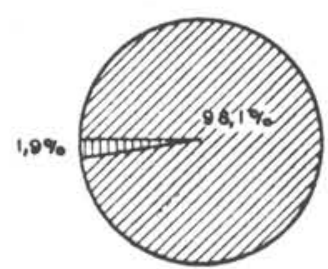

FEV.

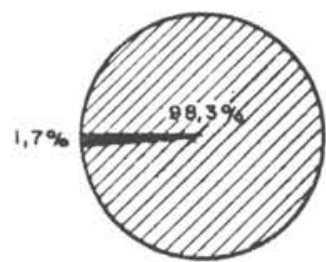

MAI.
Biddulphia regia

Choetoceros Sp.

Coscinodiscus centralis

\section{Outras diatomáceas}

Outras microalgas

\section{Fig. 3 - Principais componentes do microfitoplancton, ocorrentes na estacāo $Z$ durante o periodo de maio/73 a maio $/ 74$.}

composição especıfica. Muitas espécies foram comuns nas tres estacoes, notando-se uma dominância quase constante das formas marinhas.

Apareceram, por vezes, espécies de águas salobras e de água doce, sobretudo na estação 6 , o que é natural, dada a localização desta estação em local onde a influência de água doce é maior. Entretanto, estas espécies nunca foram dominantes ou abundantes.

\section{Discussão e conclusōes}

Qualitativamente o microfitoplâncton apresentou-se com uma composição bastante semelhante a do Canal de Santa Cruz, não apresentando grandes variações com respeito a informações obtidas anteriormente (Eskinazi-Leça, 1974). As diatomáceas marinhas foram as algas planctônicas mais abundantes, o que vem indicar uma grande influência das águas do Canal no estuário do Rio Igarassu, principalmente quanto ao aporte de águas de alta salinidade durante as preamares, fatos aliás, já demonstrado por Macêdo et al. (1973). Este florescimento de formas marinhas em estuários tem sido apontado por outros autores (Bainbridge, 1960; Teixeira \& Kutner, 1963; Sampayo, 1970), os quais também evidenciaram a importância das diatomáceas nestes ambientes, como os organismos responsáveis pelo aumento do fitoplâncton total.
Os estudos realizados no estuário do rio Igarassu, apesar de estarem em fase inicial, têm demonstrado a presença de uma flora diatomológica relativamente rica, com a ocorrência de uma grande variedade de espécies. Destas, apenas quatro apareceram de forma abundante, o que é comum em ambientes estuarinos, onde a flora fitoplânctônica tende a ser abundante, embora seja limitado o número de espécies predominantes (Riley, 1967). Na área presentemente estudada, as espécies dominantes foram: Coscinodiscus centralis, Biddulphia regia, Rhizosolenia setigera var. daga e Chae. toceros $\mathrm{sp}$, todas consideradas marinhas eurialinas.

Por outro lado, a composição qualitativa do fitoplâncton parece demonstrar qualidades de fertilidade à água, uma vez que não foram identificadas espécies que pudessem indicar algum grau de poluição ao local, apesar dos resíduos industriais que são lançados no curso inferior do rio. Deve-se considerar porém, que as estaçס̄es estudadas localizam-se próximas ao Canal de Santa Cruz, o qual poderia favorecer uma contínua diluição das águas, impedindo a instalação de espécies polissapróbias. Outros estudos em estações mais afastậas do Canal deverão ser realizados para uma melhor comprovação dos resultados presentemente obtidos. Porém, se for levado em consideração o percurso estudado, pode-se concluir que o aporte das águas do rio Igarassu, não estão influindo de maneira perniciosa, nas férteis águas do Canal de Santa Cruz. Os teores de oxigênio dissolvido e sais nutrientes, observados por Macêdo et al., (1973) também justificam tal afirmativa. 


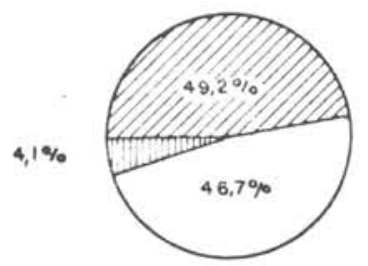

MAI.

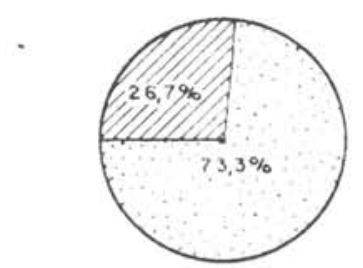

AGO.

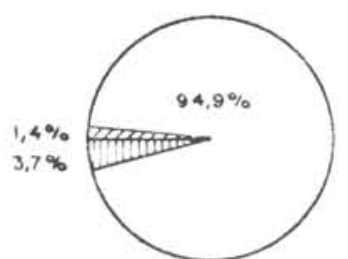

DEZ

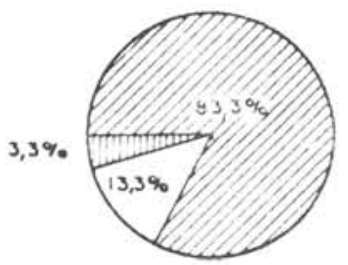

MAR

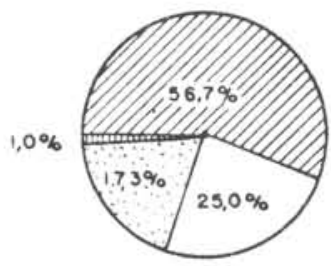

JUN.

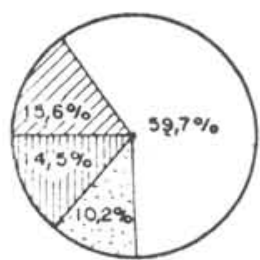

OUT.

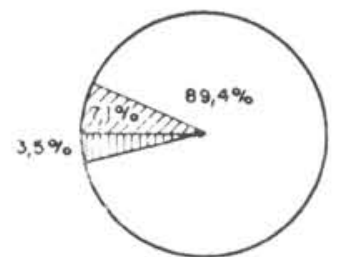

JAN.

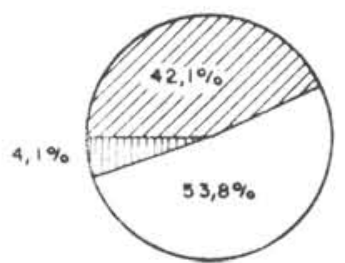

ABR.

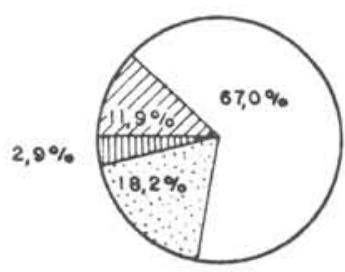

JUL.

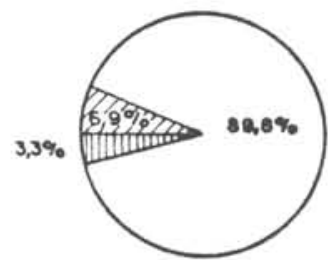

NOV.

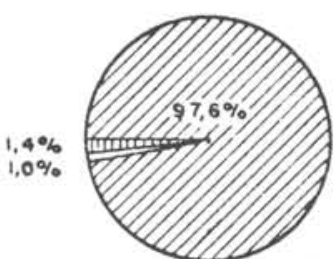

FEV.

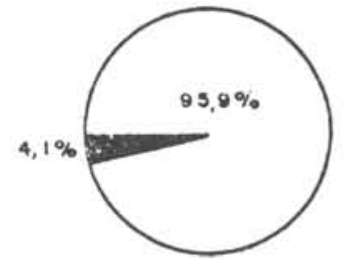

MAI.

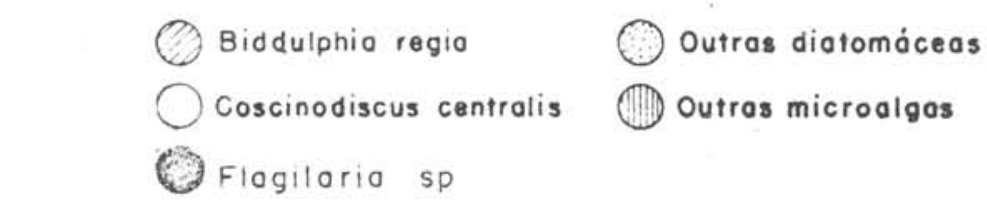

Fig. 4 - Principais componentes do microfitoplancton, ocorrentes na estaçä Zl, durante o periodo de maio/73a maio/

74.

\section{Bibliografia}

BAINBRIDGE, V. 1960. The plankton of inshore waters off Freetown, Sierra Leone. Fishery Publs col. Off., 13:1-47.

ESKINAZI-LEÇA. E. 1974. Composição e distribuição do microfitoplâncton na região do Canal de Santa Cruz (Pernambuco Brasil). Tese de livre-docência. Recife, Universidade Federal de Pernambuco, Instituto de Biociências.

HULBURT, E.M. 1956. Phytoplankton of Great Pond. Massachussets. Biol. Bull. mar. biol. Lab., Woods Hole, 110 (2) : 157 . 168.

MACÊDO, S. J.; LIRA, M. E. \& SILVA, J. E. 1973. Condições hidrológicas do Canal de Santa Cruz, Itamaracá, PE. I. Parte sul. Bolm Recursos nat., SUDENE, Recife, 11 (1/2) :55-92.

MüLLER-MELCHERS, F.C. \& FERRANDO, H.J. 1956. Técnicas para el estudio de las diatomeas. Bolm Inst. oceanogr., S Paulo, $7(1 / 2): 151-160$.

PARANAGUÁ, M.N.; NASCIMENTO, D.A. \& MACÊDO, S.J. Estudo ecológico da região de Itamaracá, Pernambuco,
Brasil. Distribuição do zooplâncton no estuário do rio Igarassu. Trabhs oceanogr. Univ. Fed. Pernambuco, Recife, 14. (no prelo).

PATRICK, R. 1967. Diatoms communities in estuaries. In: Lauff, G.H., ed. - Estuaries. Washington, Am. Ass. Adv. Sci., p. $311-315$.

RILEY, G.A. 1952. Phytoplankton of Block Island Sound, 1949. Bull. Bingham oceanogr. Coll., 2 : 252-270.

ed. Estuaries. Washington, Am. Ass. Adv. Sci., p. 316-326.

SAMPAYO, M.A.M. 1970. Diatomáceas do estuário do Sado. Estudo qualitativo e quantitativo: variações sazonais. Notas Estud. Inst. Biol. mar., Lisb., (39) : 1-104.

TEIXEIRA, C. \& KUTNER, M.B.B. 1963. Plankton studies in a mangrove enviroment. I - First assessment of - anding-stock and principal ecological factors. Bolm Inst. oceanogr., S Paulo, 12 (3) : 101-124.

TUNDISI, J. 1970. O plâncton estuarino. Contrçôes Inst. oceanogr. Univ. S. Paulo, sér. Oceanogr. biol., (19): 1-22. 